\title{
Re-assessment of 30-, 60- and 90-day mortality rates in non- metastatic prostate cancer patients treated either with radical prostatectomy or radiation therapy
}

\author{
Jens Hansen, MD; ${ }^{*+}$ Giorgio Gandaglia, MD, ${ }^{*}$ S Marco Bianchi, MD,; Maxine Sun, BSc; ${ }^{*}$ Michael Rink, MD; ${ }^{* \pm}$ \\ Zhe Tian, BSc,; Malek Meskawi, MD; ${ }^{*}$ Quoc-Dien Trinh, MD; Shahrokh F. Shariat, MD;: Paul Perrotte, MD;* \\ Felix K.-H. Chun, MD;a Markus Graefen, MD; Pierre I. Karakiewicz, MD, FRCSC ${ }^{*}$
}

\begin{abstract}
*Cancer Prognostics and Health Outcomes Unit, University of Montreal Health Centre, Montreal, QC; † Martini Clinic, Prostate Cancer Center Hamburg-Eppendorf, Hamburg, Germany; ${ }^{\S}$ Department of Urology, Vita-Salute San Raffaele University, Milan, Italy; ${ }^{*}$ Department of Urology, University of Montreal Health Centre, Montreal, QC; ${ }^{ \pm}$Department of Urology, Weill Medical College of Cornell University, New York, NY; §Vattikuti Urology Institute, Henry Ford Health System, Detroit, Ml; ${ }^{\circ}$ University Hospital Hamburg-Eppendorf, Hamburg, Germany
\end{abstract}

Cite as: Can Urol Assoc J 2014;8(1-2):e75-80. http://dx.doi.org/10.5489/cuaj.749 Published online February 12, 2014.

\section{Abstract}

Introduction: It is customary to consider deaths that occur within 90 days of surgery as caused by that surgery. However, such practice may overestimate the true short-term mortality rates after radical prostatectomy (RP). Indeed, treatment-unrelated events might affect short-term mortality rates. We assess RP-specific excess short-term mortality.

Methods: We performed a retrospective analysis of a populationbased cohort of 59010 patients (RP $=28281$ and external beam radiation therapy [EBRT] as reference group, $n=30729$ ) who were treated between 1998 and 2005 for non-metastatic prostate cancer. Using univariate and multivariate logistic regression analyses, we assessed the rates of 30-, 60- and 90-day mortality after either RP or EBRT.

Results: Within the cohort, 30-, 60- and 90-day mortality rates were $0.2,0.5$ and $0.6 \%$, and $0.1,0.4$ and $0.6 \%$ for RP and EBRT patients, respectively. This resulted in overall 30-, 60, and 90- day mortality differences of $0.1,0.1$ and $0 \%$, respectively. After stratification according to age and Charlson comorbidity index (CCI), the magnitude of these differences increased up to $3.2 \%$ in favour of EBRT in patients aged $>75$ years with $\mathrm{CCl} \geq 2$. In multivariable analysis, rates of 30-, 60- and 90- day mortality were 5.2-, 1.8and 1.3-fold higher after RP than EBRT, respectively. Our study is limited by its non-randomized design.

Conclusion: Overall, absolute short-term mortality rates after RP are comparable to those of EBRT. The difference decreases over time: 90 days $<60$ days $<30$ days. Nonetheless, their magnitude is far from trivial in the elderly and sickest patients.

\section{Introduction}

Postoperative short-term mortality after radical prostatectomy (RP) for prostate cancer is the ultimate risk when sur- gery is chosen instead of other treatments. Reported overall short-term mortality rates after RP range from 0.1 to $1.0 \% .^{1-7}$ However, these rates originate from institutional or population-based datasets, where all deaths regardless of cause are recorded. ${ }^{1-7}$ Only one study has accounted for baseline mortality rates. ${ }^{8}$

It is customary to define a death that occurred within 90 days from surgery as caused by that surgery. ${ }^{1,2,5,7,9,10}$ Such practice may overestimate the short-term mortality related to the surgical procedure itself. Some individuals may die of RP-unrelated causes. Medical causes of death may also occur in individuals who were not exposed to a surgical intervention. For example, such events might occur in patients treated with external beam radiation therapy (EBRT), which is not known to predispose to higher mortality. Consequently, short-term mortality after EBRT might be considered as baseline mortality in patients with clinically localized prostate cancer. In this analysis, we examined short-term mortality rates after either RP or EBRT. We proposed that short-term mortality rates recorded after EBRT may represent the allcause mortality in patients with localized prostate cancer. Conversely, a proportion of deaths after RP is clearly related to the surgery itself. The differences between the two rates may represent the events directly caused by the RP.

\section{Methods}

\section{Data source}

Patients with histologically confirmed prostate cancer between 1998 and 2005 were identified relying on the Surveillance Epidemiology and End Results (SEER) Medicare insurance program-linked database. ${ }^{11}$ The SEER regions represent about $14 \%$ of the US population before 2000 and $26 \%$ thereafter, while the Medicare insurance program cov- 
Hansen et al.

ers about $97 \%$ of the US population aged $\geq 65$ years, as previously described. ${ }^{12,13}$

\section{Study population}

We identified 108369 men aged $\geq 65$ years with prostate cancer (International Classification of Diseases [ICD]-9: 61.9; histologic code: 8140) who were treated either with RP or EBRT. We excluded patients treated with prostate brachytherapy ( $n=32239)$, distant metastases $(n=4271)$, missing follow-up $(n=10670)$ and/or missing tumour grade $(\mathrm{n}=2179)$. In total, we included 59010 assessable individuals.

\section{Examined risk factors}

Age was examined both as a continuous and categorical variable ( $\geq 65-70$ vs. $71-75$ vs. $>75$ years). Race, socioeconomic status, marital status and year of surgery were provided by the SEER-Medicare database. Charlson comorbidity index $(\mathrm{CCl})$ was derived from Medicare claims during the year prior to prostate cancer diagnosis, ${ }^{14}$ and categorized as 0 vs. 1 vs. $\geq 2$. Tumour grade was defined as "well differentiated," "moderately differentiated" and "poorly differentiated." To define clinical stage (CS), we used the clinical extension information provided by the SEER database..$^{15}$

Treatment type was identified searching outpatient claims and Part A and B Medicare files for the appropriate ICD-9 and Healthcare Common Procedure Coding System codes. ${ }^{15}$ RP was identified using the Current Procedural Terminology, $4^{\text {th }}$ edition codes: 55840, 55842, 55845, and 55866. ${ }^{12,16}$ Subsequently, EBRT was identified using procedure codes, as previously described. ${ }^{17}$

\section{Definition of 30-day, 60-day and 90-day mortality}

Any kind of death within 1 month after RP or within 1 month of starting radiotherapy was defined as 30-day mortality. A similar definition was applied for 60- and 90-day mortality.

\section{Statistical analyses}

The Mann-Whitney test and chi-square test were used to compare the statistical significance of differences in medians and proportions, respectively. Multivariable logistic regression analyses were performed to test the statistical significance of the difference in short-term mortality rates between RP and EBRT. Adjustment was made for age, CCl, race, marital status, socioeconomic status (SES) and clinical stage. All statistical analyses were performed using R statistical package system (Vienna, Austria), with a two-sided significance level set at 0.05 .

\section{Results}

\section{Patient characteristics}

Overall, 28281 men (48\%) were treated with RP, whereas 30729 men (52\%) underwent EBRT. Median ages were 68 and 73 years for RP and EBRT, respectively $(p<0.001)$. RP patients were more likely to have lower $\mathrm{CCl}$ status, to be Caucasian, to have high SES, to be married, and to have higher clinical stage (all $p<0.001$ ), whereas RP patients were less likely to have poorly differentiated tumour grade $(p<0.001)$ (Table 1).

\section{0-day, 60-day and 90-day mortality rates}

The overall 30-day mortality rates after RP were $0.2 \%$ $(\mathrm{n}=63)$ versus $0.1 \%(\mathrm{n}=18)$ after EBRT $(p<0.001)$. The 60 -day mortality rates were respectively $0.5 \%(n=135)$ versus $0.4 \%(n=111)$ after EBRT $(p=0.03)$, whereas the 90 -day mortality rates after RP were $0.6 \%(n=170)$ versus $0.6 \%$ $(\mathrm{n}=193)$ after EBRT $(p=0.7)$ (Table 2$).$

\section{Stratification according to age}

Stratification of short-term mortality at 30 days according to age revealed rates of 0.2 versus $0.1 \%, 0.3$ versus $0 \%$, and 0.7 versus $0 \%$ for age categories $\geq 65-70,71-75$ and $>75$ years, after RP or EBRT patients, respectively. At 60 days, the rates were 0.3 versus $0.5 \%, 0.6$ versus $0.3 \%$, and 1.9 versus $0.3 \%$ for age categories $\geq 65-70,71-75$, and $>75$ years, respectively. Finally, at 90 days, the short-term mortality rates were 0.3 versus $0.8 \%, 0.7$ versus $0.5 \%$, and 2.8 versus $0.5 \%$ for age categories $\geq 65-70,71-75$ and $>75$ years, respectively. Short-term mortality differences between different age categories were statistically significant within RP patients at every time points (all $p<0.001$ ) (Table 2).

\section{Stratification according to $\mathrm{Cl}$}

Stratification of short-term mortality at 30 days according to $\mathrm{CCl}$ revealed short-term mortality rates of 0.2 versus $0.1 \%$, 0.2 vs. $0.1 \%$, and 0.4 versus $0.1 \%$ for $\mathrm{CCl}$ categories 0,1 and $\geq 2$, after RP or EBRT, respectively. At 60 days, recorded rates were 0.4 versus $0.4 \%, 0.7$ versus $0.3 \%$, and 0.9 versus $0.5 \%$ for $\mathrm{CCl}$ categories 0,1 and $\geq 2$ in RP and EBRT patients, respectively. Finally, at 90 days, short-term mortality rates were 0.5 versus $0.6 \%, 0.9$ versus $0.5 \%$, and 1.3 versus $0.8 \%$ for $\mathrm{CCl}$ categories 0,1 , and $\geq 2$ in men treated with RP and EBRT, respectively. Short-term mortality differences between different $\mathrm{CCl}$ categories were only statistically significant within RP patients at 60 and 90 days after RP (both $p<0.001$ ). 


\begin{tabular}{|c|c|c|c|c|}
\hline No. (\%) & $59010(100)$ & 28281 (48\%) & $30729(52 \%)$ & - \\
\hline $\begin{array}{l}\text { Year of treatment } \\
2004-2005 \\
2002-2003 \\
2000-2001 \\
1998-1999\end{array}$ & $\begin{array}{c}27722(30.4) \\
26164(28.7) \\
24649(27) \\
12714(13.9)\end{array}$ & $\begin{array}{l}8554(30.2) \\
7878(27.9) \\
7436(26.3) \\
4413(15.6)\end{array}$ & $\begin{array}{l}9415(30.6) \\
8843(28.8) \\
8209(26.7) \\
4262(13.9)\end{array}$ & $<0.001$ \\
\hline $\begin{array}{l}\text { Clinical stage } \\
\text { T1 } \\
\text { T2 } \\
\text { T3/T4 } \\
\text { Unknown }\end{array}$ & $\begin{array}{c}35653(39.1) \\
49969(54.8) \\
4093(4.5) \\
1534(1.7)\end{array}$ & $\begin{array}{c}9349(33.1) \\
17029(60.2) \\
1484(5.2) \\
419(1.5)\end{array}$ & $\begin{array}{c}12485(40.6) \\
16310(53.1) \\
1586(5.2) \\
348(1.1)\end{array}$ & $<0.001$ \\
\hline $\begin{array}{l}\text { Lymph node status } \\
\text { N0 } \\
\text { N1 } \\
\text { Nx }\end{array}$ & $\begin{array}{c}79740(87.4) \\
1198(1.3) \\
10311(11.3)\end{array}$ & $\begin{array}{c}26153(92.5) \\
600(2.1) \\
1528(5.4)\end{array}$ & $\begin{array}{c}26191(85.2) \\
252(0.8) \\
4286(13.9)\end{array}$ & $<0.001$ \\
\hline $\begin{array}{l}\text { Tumour grade } \\
\text { Well differentiated } \\
\text { Moderatly differentiated } \\
\text { Poorly differentiated }\end{array}$ & $\begin{array}{c}2265(2.5) \\
59348(65) \\
29636(32.5)\end{array}$ & $\begin{array}{c}596(2.1) \\
18046(63.8) \\
9639(34.1)\end{array}$ & $\begin{array}{c}703(2.3) \\
19095(62.1) \\
10931(35.6)\end{array}$ & $<0.001$ \\
\hline $\begin{array}{l}\text { Socioeconomic status } \\
\text { High } \\
\text { Low }\end{array}$ & $\begin{array}{l}50558(55.4) \\
39829(43.6)\end{array}$ & $\begin{array}{l}16090(56.9) \\
11955(42.3)\end{array}$ & $\begin{array}{l}16626(54.1) \\
13810(44.9)\end{array}$ & $<0.001$ \\
\hline $\begin{array}{l}\text { Marital status } \\
\text { Married } \\
\text { Single } \\
\text { Unknown }\end{array}$ & $\begin{array}{c}68075(74.6) \\
17503(19.2) \\
5671(6.2)\end{array}$ & $\begin{array}{c}22145(78.3) \\
4831(17.1) \\
1305(4.6)\end{array}$ & $\begin{array}{c}22197(72.2) \\
6475(21.1) \\
2057(6.7)\end{array}$ & $<0.001$ \\
\hline
\end{tabular}

RP: radical prostatectomy; EBRT: external beam radiation therapy; RT: radiation therapy; CCl: Charlson comorbidity index.

\section{Multivariate logistic regression analyses}

In multivariate logistic regression analyses for the entire cohort, at 30, 60 and 90 days after treatment, the shortterm mortality risks were $5.2(p<0.001), 1.8(<0.001)$ and 1.3 -fold ( $p=0.04$ ) higher after RP compared to EBRT.

\section{Discussion}

The absolute short-term mortality rates after any surgical procedure are usually interpreted as related to that procedure. This assumption may overestimate the rate of events related to the surgery. The causality of events observed after surgery cannot be validly ascertained. Some cardiovascular events may be precipitated by the surgical treatment, others may have occurred regardless of the surgery. Events that occur immediately after surgery are more likely to be related to surgical risks. Conversely, events that occur within longer 


\begin{tabular}{|c|c|c|c|c|}
\hline & $\mathbf{R P}$ & EBRT & $\begin{array}{c}\text { RP-specific } \\
\text { excess mortality } \\
\text { rates }\end{array}$ & $\begin{array}{c}p \\
\text { value }\end{array}$ \\
\hline $\begin{array}{l}\text { 30-day mortality, } \\
\text { no. (\%) }\end{array}$ & $63(0.2)$ & $18(0.1)$ & 0.1 & $<0.001$ \\
\hline $\begin{array}{l}60 \text {-day mortality, } \\
\text { no. }(\%)\end{array}$ & $135(0.5)$ & $111(0.4)$ & 0.1 & 0.03 \\
\hline $\begin{array}{l}\text { 90-day mortality, } \\
\text { no. (\%) }\end{array}$ & $170(0.6)$ & $193(0.6)$ & 0 & 0.7 \\
\hline
\end{tabular}

RP: radical prostatectomy; EBRT: external beam radiation therapy.

periods may more frequently be unrelated to the surgical stress. To the best of our knowledge, only one study has accounted for treatment-unrelated deaths within 30 days after RP, relying on older data. ${ }^{8}$

The distinction between surgery-induced events and surgery-unrelated events could ideally be examined within a randomized trial. However, in the context of localized prostate cancer, such design is virtually impossible to implement. An alternative consists of an observational design, with adjustment for confounders.

In the current analysis, we relied on such a design. Specifically we compared 30-, 60-, and 90-day mortality rates between RP and EBRT patients. We hypothesized that short-term mortality after EBRT may be interpreted as events that occurred independently of treatment delivery. These events may therefore be considered as the background shortterm mortality in patients with prostate cancer. Conversely, a proportion of short-term mortality that occurs after RP is directly attributable to the surgery itself. We relied on shortterm mortality rates after RP and EBRT and we calculated the difference between these rates after EBRT and RP to estimate baseline- short-term mortality. This difference may indicate the excess short-term mortality related to RP itself. Since EBRT patients may be sicker and older than RP patients, we relied on multivariate analyses to adjust for these differences.

Our results showed that 30-, 60-, and 90-day mortality rates for the entire cohort were $0.2,0.5$ and $0.6 \%$ versus 0.1 , 0.4 and $0.6 \%$ for RP and EBRT patients, respectively. The differences between RP and EBRT rates were $0.1,0.1$ and $0 \%$ for the entire cohort at 30,60, and 90 days. These results indicate that short-term mortality rates after RP are low and that short-term mortality rates after EBRT are even lower. The absolute differences are marginal at 30 and 60 days and virtually disappear within the overall population at 90 days after treatment. In the literature, short-term mortality within 30 days after RP ranges from $0.1 \%$ to $1.0 \%{ }^{1,2,4-6}$ However, these studies did not account for background noise. One study previously performed a similar approach like we did and accounted for baseline mortality. The authors of this study reported an overall excess 30-day mortality after RP of $0.3 \%{ }^{8}$ Even if their approach is similar to ours, the main difference consists of the reference group that was used to account for background noise. They defined mortality within 7 to 12 months after RP as baseline mortality, ${ }^{8}$ whereas we used short-term mortality after EBRT as a reference.

The discrepancy between the unadjusted absolute differences was further explored in stratified univariable analyses. The intent of those was to uncover the patient characteristics that may predispose to the difference of largest magnitude in absolute or relative terms. Since age and comorbidities represent the most established contributors to short-term mortality, we relied on these variables for the bivariate analyses. ${ }^{1,2}$ In bivariate analyses, the magnitude of the difference between RP and EBRT was most pronounced in the oldest and sickest individuals. These data corroborate previous reports of increasing short-term mortality with increasing age and comorbidities. ${ }^{1,2}$ Unfortunately, due to small numbers of events, multivariate stratified analyses were not possible. Conversely, Alibhai and colleagues reported that short-term mortality rates were not substantially higher in older patients compared to their younger counterpart. Particularly, they reported an absolute excess mortality risk within 30 days after RP of 0.51 and 0.59 for patients aged 60 to 69 and 70-79, respectively. ${ }^{8}$ A valid comparison of our results to the results of Alibhai and colleagues is difficult due to the different age categories that were used. However, even if 30-day mortality rates in our cohort were generally low, we recorded higher short-term mortality excess for patients aged $>75$ relative to those aged 65 to 70 .

The discrepancy between absolute rate differences that were marginal and relative differences that were meaningful and statistically significant requires careful consideration. Unadjusted rates may be subjected to biases that distinguish RP patients from their EBRT counterparts. Indeed, within our cohort, EBRT patients were older and sicker. This difference in patient characteristics may have obliterated shortterm mortality rates between RP and EBRT. To correct for potential biases and confounding variables, we performed multivariate analyses. The results within the entire cohort indicated a 5.2-, 1.8- and 1.4-fold increase in respectively 30-, 60- and 90-day short-term mortality (all statistically significant).

Taken together, our results imply that RP may be performed very safely in young and fit individuals, whereas older and sicker patients may be at higher risk of short-term mortality. Sub-analyses confirm this hypothesis. Specifically, when age and comorbidities increase, the short-term mortality excess rates increase proportionately. This may be interpreted as an indicator of increasing caution, when RP is contemplated relative to EBRT.

Despite this added perspective, our study is limited by its non-randomized design. We adjusted for available confounders to minimize the effect of biases. Unfortunately, 
Short-term mortality after radical prostatectomy

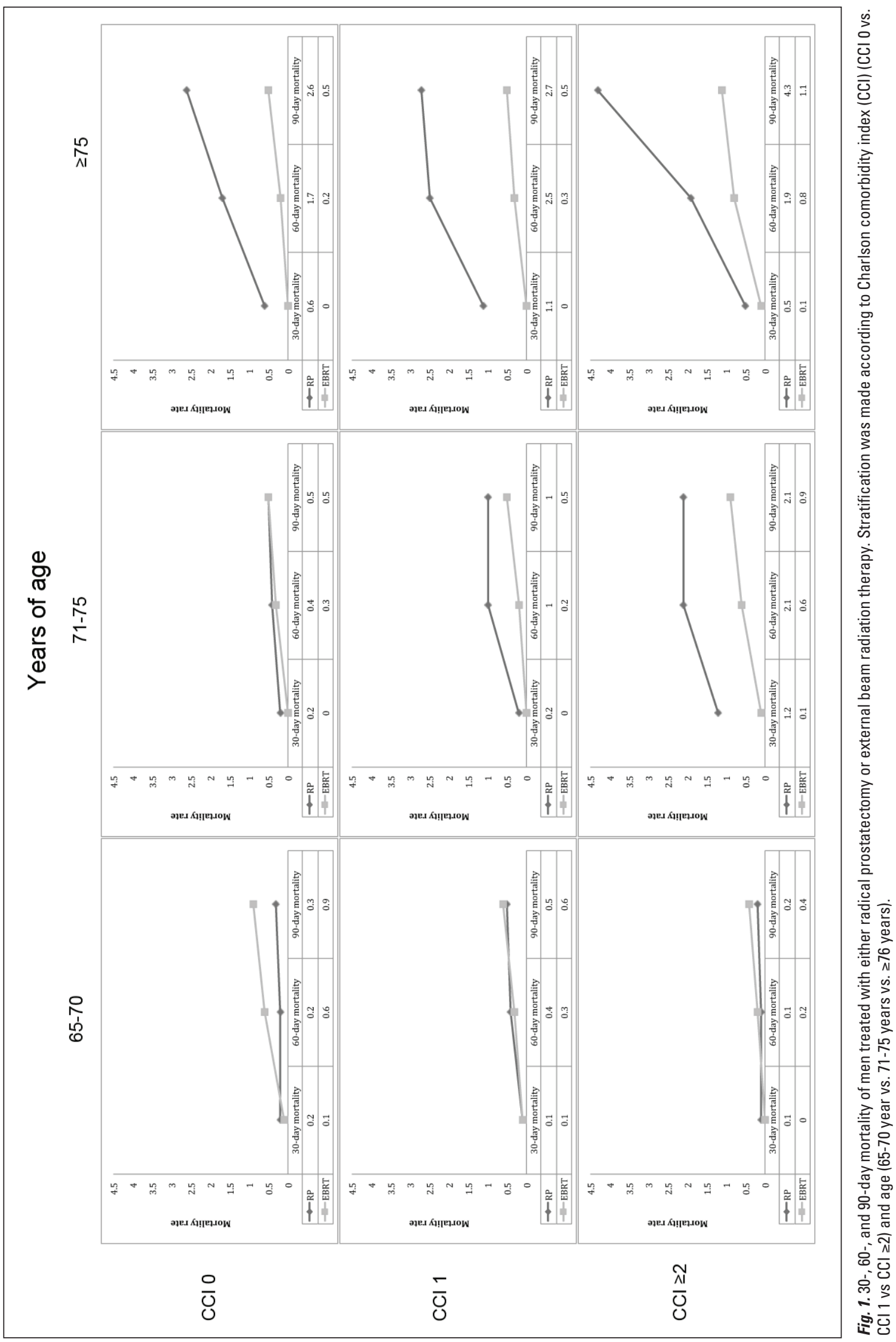


residual confounders and effect of biases have remained. Use of data from randomized trials may obviate this issue. However, to date these trials have had less than 400 patients per arm. ${ }^{18,19}$ In consequence, their statistical power would have been insufficient to validly assess short-term mortality rates after either EBRT or RP. It is of note that, even in our extensive population-based cohort, events were at times infrequent in some age and $\mathrm{CCl}$ strata.

\section{Conclusion}

Absolute short-term mortality rates after RP are comparable to those of EBRT. The differences decrease over time: 90 days $<60$ days $<30$ days. Nonetheless, their magnitude is far from trivial in the elderly and sickest patients. These observations imply that surgery may be safely performed in young and fit individuals, whereas older and sicker patients should be considered at higher risk of short-term mortality.

Competing interests: Dr. Hansen, Dr. Gandaglia, Dr. Bianchi, Dr. Sun, Dr. Rink, Dr. Tian, Dr. Meskawi, Dr. Trinh, Dr. Shariat, Dr. Perrotte, Dr. Chun, Dr. Graefen and Dr. Karakiewicz all declare no competing financial or personal interests.

This paper has been peer-reviewed.

Acknowledgments: Jens Hansen and Gandaglia both contributed equally to this manuscript. Pierre I. Karakiewicz is partially supported by the University of Montreal Health Centre Urology Specialists, Fonds de la Recherche en Sante du Quebec, the University of Montreal Department of Surgery and the University of Montreal Health Centre (CHUM) Foundation.

\section{References}

1. Walz J, Montorsi F, Jeldres C, et al. The effect of surgical volume, age and comorbidities on 30-day mortality after radical prostatectomy: A population-based analysis of 9208 consecutive cases. BJU Int 2008;101:826-32. http://dx.doi.org/10.1111/j.1464-410X.2007.07373.x

2. Alibhai $S M$, Leach $M$, Tomlinson $G$, et al. 30-day mortality and major complications after radical prostatectomy: Influence of age and comorbidity. J Natl Cancer Inst 2005;97:1525-32. http://dx.doi. org/10.1093/inci/dij313
3. Konety BR, Allareddy V, Modak S, et al. Mortality after major surgery for urologic cancers in specialized urology hospitals: Are they any better? J Clin Oncol 2006;24:2006-12. http://dx.doi.org/10.1200/ JC0.2005.04.2622

4. Loppenberg B, Noldus J, Holz A, et al. Reporting complications after open radical retropubic prostatectomy using the Martin criteria. J Urol 2010;184:944-8. http://dx.doi.org/10.1016/i.juro.2010.05.032

5. Karakiewicz PI, Bazinet $M$, Aprikian $A G$, et al. Thirty-day mortality rates and cumulative survival after radical retropubic prostatectomy. Urology 1998;52:1041-6. http://dx.doi.org/10.1016/S00904295(98)00350-1

6. Judge A, Evans S, Gunnell DJ, et al. Patient outcomes and length of hospital stay after radical prostatectomy for prostate cancer: Analysis of hospital episodes statistics for England. BJU Int 2007;100:1040-9.

7. Alibhai SM, Leach M, Warde P. Major 30-day complications after radical radiotherapy: A populationbased analysis and comparison with surgery. Cancer 2009;115:293-302. htrp://dx.doi.org/10.1002/ cncr.24008

8. Alibhai SM, Leach M, Tomlinson G, et al. Rethinking 30-day mortality risk after radical prostatectomy. Urology 2006;68:1057-60. http://dx.doi.org/10.1016/i.urology.2006.06.016

9. Stimson CJ, Chang SS, Barocas DA, et al. Early and late perioperative outcomes following radical cystectomy: 90-day readmissions, morbidity and mortality in a contemporary series. J Urol 2010;184:1296-300. http://dx.doi.org/10.1016/i.juro.2010.06.007

10. Alibhai $S M$, Leach $M$, Tomlinson $G$. Examining the location and cause of death within 30 days of radical prostatectomy. BJU Int 2005;95:541-4. http://dx.doi.org/10.1111/j.1464-410X.2005.05335.x

11. SEER Cancer Statistics Review, 1975-2004. National Cancer Institute Web site. Bethesda, MD. http:// seer.cancer.gov/csr/1975_2004. Accessed January 29, 2013.

12. Abdollah F, Sun M, Schmitges J, et al. Cancer-specific and other-cause mortality after radical prostatectomy versus observation in patients with prostate cancer: Competing-risks analysis of a large North American population-based cohort. Eur Urol 2011;60:920-30. http://dx.doi.org/10.1016/i.eururo.2011.06.039

13. Warren JL, Klabunde CN, Schrag D, et al. Overview of the SEER-Medicare data: content, research applications, and generalizability to the United States elderly population. Med Care 2002;40:IV-1:IV-117. http://dx.doi.org/10.1097/00005650-200208001-00002

14. Klabunde CN, Potosky AL, Legler JM, et al. Development of a comorbidity index using physician claims data. J Clin Epidemiol 2000;53:1258-67. http://dx.doi.org/10.1016/50895-4356(00)00256-0

15. Wong YN, Mitra N, Hudes G, et al. Survival associated with treatment vs observation of localized prostate cancer in elderly men. JAMA 2006;296:2683-93. htrp://dx.doi.org/10.1001/jama.296.22.2683

16. American Medical Association. Current procedural terminology. $4^{\text {th }}$ edition. Chicago, IL: American Medical Association; 2001.

17. Lowrance WT, Ekkin EB, Yee DS, et al. Locally advanced prostate cancer: A population-based study of treatment patterns. BJU Int 2012;109:1309-14. http://dx.doi.org/10.1111/j.1464-410X.2011.10760.x. Epub 2011 Nov 15

18. Bill-Axelson A, Holmberg L, Ruutu M, et al. Radical prostatectomy versus watchful waiting in early prostate cancer. N Engl J Med 2011;364:1708-17. http://dx.doi.org/10.1056/NEJMoa1011967

19. Wilt TJ, Brawer MK, Jones KM, et al. Radical prostatectomy versus observation for localized prostate cancer. N Engl J Med 2012;367:203-13. http://dx.doi.org/10.1056/NEJMoal 113162

Correspondence: Dr. Giorgio Gandaglia, University of Montreal Health Centre, 1058, rue St-Denis, Montreal, QC, H2X 3J4; giorgan10@libero.it 